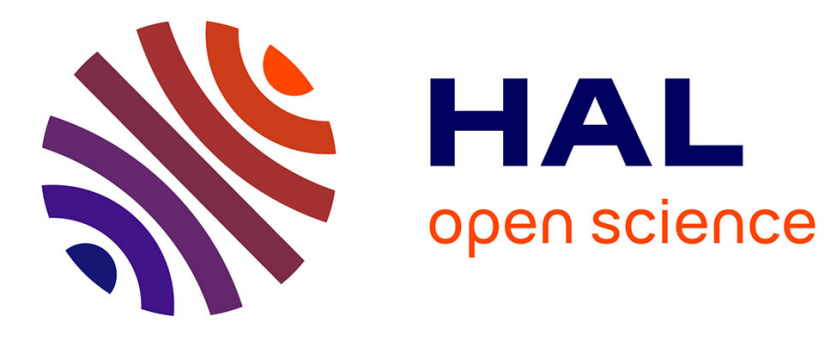

\title{
Biological response to purification and acid functionalization of carbon nanotubes
}

\author{
Agathe Figarol, Jérémie Pourchez, Delphine Boudard, Valérie Forest, \\ Jean-Marc Tulliani, Jean-Pierre Lecompte, Michèle Cottier, Didier \\ Bernache-Assollant, Philippe Grosseau
}

\section{To cite this version:}

Agathe Figarol, Jérémie Pourchez, Delphine Boudard, Valérie Forest, Jean-Marc Tulliani, et al.. Biological response to purification and acid functionalization of carbon nanotubes. Journal of Nanoparticle Research, 2014, 16, pp.2507. 10.1007/s11051-014-2507-y · hal-01017203

\section{HAL Id: hal-01017203 https://hal.science/hal-01017203}

Submitted on 3 Jul 2014

HAL is a multi-disciplinary open access archive for the deposit and dissemination of scientific research documents, whether they are published or not. The documents may come from teaching and research institutions in France or abroad, or from public or private research centers.
L'archive ouverte pluridisciplinaire HAL, est destinée au dépôt et à la diffusion de documents scientifiques de niveau recherche, publiés ou non, émanant des établissements d'enseignement et de recherche français ou étrangers, des laboratoires publics ou privés. 


\title{
Biological Response to Purification and Acid Functionalization of Carbon
}

\author{
Nanotubes
}

Agathe Figarol *, Jérémie Pourchez *, Delphine Boudard, Valérie Forest, Jean-Marc Tulliani, JeanPierre Lecompte, Michèle Cottier, Didier Bernache-Assollant, Philippe Grosseau

A. Figarol (Corresponding Author), P. Grosseau

Ecole Nationale Supérieure des Mines, SPIN-EMSE, CNRS: UMR 5307, LGF, Propice Department 158, Cours Fauriel, F-42023 Saint-Etienne, France

E-mail: figarol@emse.fr

A. Figarol (Corresponding Author), J. Pourchez (Corresponding Author), V. Forest, D. BernacheAssollant

Ecole Nationale Supérieure des Mines, CIS-EMSE, EA 4624, SFR IFRESIS, LINA, BioPi Department 158, Cours Fauriel, F-42023 Saint-Etienne, France

E-mail : pourchez@emse.fr

D. Boudard, M. Cottier

Université Jean Monnet Saint-Etienne, EA 4624, SFR IFRESIS, LINA,

Faculté de Médecine Jacques Lisfranc

15, rue Ambroise Paré, F-42023 Saint-Etienne, France

CHU de Saint-Etienne,

F-42055, Saint-Etienne, France

J.-M. Tulliani

Politecnico di Torino, Department of Applied Science and Technology,

10129 Torino, Italy

J.-P. Lecompte

SPCTS Centre Européen de la Céramique CNRS: UMR 7315,

F-87068 Limoges, France 
* Correspondence to: figarol@ gmail.com +334 77420213 or pourchez@ gmail.com +334 77420180

\section{TABLE OF CONTENT}

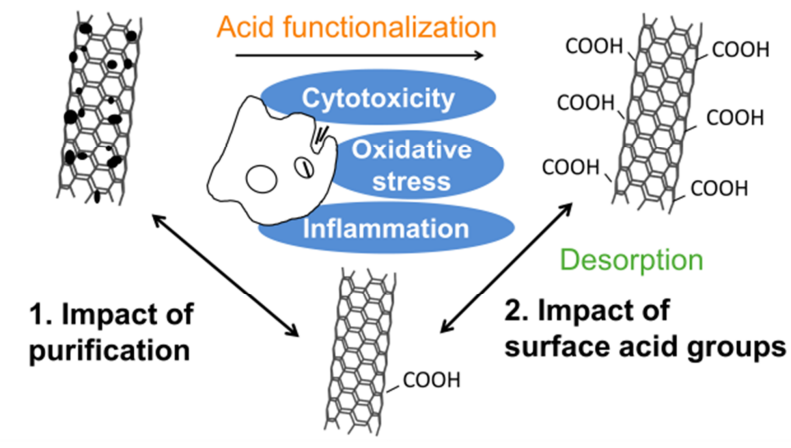

ABSTRACT: Acid functionalization has been considered as an easy way to enhance the dispersion and biodegradation of carbon nanotubes (CNT). However, inconsistencies between toxicity studies of acid functionalized CNT remain unexplained. This could be due to a joint effect of the main physicochemical modifications resulting from an acid functionalization: addition of surface acid groups, and purification from catalytic metallic impurities. In this study the impact on CNT bio-toxicity of these two physiochemical features was assessed separately. The in vitro biological response of RAW 264.7 macrophages was evaluated after exposure to 15 to $240 \mu \mathrm{g} \cdot \mathrm{mL}^{-1}$ of two types of multi-walled CNT. For each type of CNT (small: $20 \mathrm{~nm}$ diameter, and big: $90 \mathrm{~nm}$ diameter), three different surface chemical properties were studied (total of six CNT samples): pristine, acid functionalized and desorbed. Desorbed CNT were purified by the acid functionalization but presented a very low amount of surface acid groups due to a thermal treatment under vacuum. A Janus effect of acid functionalization with two opposite impacts is highlighted. The CNT purification decreased the overall toxicity, while the surface acid groups intensified it when present at a specific threshold. These acid groups especially amplified the proinflammatory response. The threshold mechanism which seemed to regulate the impact of acid groups should be further studied to determine its value and potential link to the other physic-chemical state of the CNT. The results suggest that, for a safer-design approach, the benefit-risk balance of an acid 
functionalization has to be considered, depending on the CNT primary state of purification. Further research should be conducted in this direction.

KEYWORDS: carbon nanotubes, health effects, nanotoxicity, surface functionalization, oxidative stress, inflammation, cytotoxicity 


\section{INTRODUCTION}

Over the past few years, the exceptional properties of carbon nanotubes (CNT) have aroused a huge interest in industrial fields as diverse as material science, microelectronics or biomedicine. High mechanical resistance, adsorption capacity, thermal and electric conductivity for example allow the development of numerous applications (Baughman et al. 2002; De Volder et al. 2013). CNT can easily be functionalized with components of interest, and this opens a wide range of possibilities, especially in the biological sector (medical imaging carriers or drug delivery) (Bianco et al. 2005; Singh et al. 2012). Nevertheless, their appearance on the market and their increasing use at the research scale raise health concerns especially regarding their structural similarities with asbestos.

CNT have small aerodynamic diameters and this gives them the potential to penetrate deeply into the lung and activate pathogenic pathways. In spite of an insufficient understanding of their biological impact, it is now well established that the physicochemical features of CNT influence their pulmonary toxicity (Simon-Deckers et al. 2008; Krug and Wick 2011; Kayat et al. 2011). In particular, their size and entanglement, their metallic impurities and their surface functionalization have been shown to affect the biological response through mechanisms and potential combinative effects that are yet to be determined. Case-by-case studies to assess each CNT toxicological feature are a dead-end time- and moneyconsuming strategy (Choi et al. 2009). It is therefore crucial to gain understanding of the physicochemical characteristics that can impact the biological responses in order to progress toward a safer by design approach (Schrurs and Lison 2012).

Functionalizing CNT surfaces by introducing changes in surface chemical properties has been proposed as a way to reduce CNT toxicity. Acid functionalization is one of the major approaches to this purpose, and is of great interest for industrial and research applications (Musso et al. 2009; Ahmadzadeh Tofighy and Mohammadi 2012; Huang et al. 2013). The decrease of CNT hydrophobicity through the newly linked surface acid groups allows a better dispersion in aqueous environment. In addition, acid attack during the functionalization process purifies the CNT from the catalytic impurities resulting from the production process (Jain et al. 2011; Dong et al. 2012). Several studies have moreover featured acid 
functionalization processes that enhance the CNT biodegradation and biocompatibility (Kagan et al. 2010; Liu et al. 2010; Bianco et al. 2011).

Despite ample research, the comprehensive impact of acid functionalization on the in vitro cellular response remains unclear. Some studies have even shown that acid functionalized CNT are more toxic than pristine ones (Gutiérrez-Praena et al. 2011; Dong et al. 2012). Results are conflicting even when selecting in vitro studies using the same cell line. Studies on murine macrophages (RAW 264.7) reported increased cytotoxicity and inflammation through the cellular internalization of acid functionalized singlewalled (SWCNTf) or multi-walled CNT (MWCNTf) (Dong et al. 2012; Wang et al. 2012). Another study showed that MWCNTf induced a reduced cytotoxicity but a slight increase of inflammation and oxidative stress (Zhang et al. 2012). Lastly, based on Fraczek-Szczypta et al. work (Fraczek-Szczypta et al. 2012), the cytotoxicity of MWCNTf remains globally unchanged compared to pristine MWCNT while they have a tendency to decrease cell proliferation.

The aim of this study was to investigate the impact of acid functionalization independently of any other parameter. It was hypothesized that part of the inconsistencies between previous studies was due to an overlap of the two main impacts of an acid functionalization on the CNT structures: addition of surface acid groups and purification by removal of catalytic impurities. To avoid a multifactorial analysis as far as possible, an original desorption process was conducted. Part of the acid functionalized CNT was treated thermally to reduce the amount of surface acid groups leaving all other physicochemical parameters unaffected. As a result of this, it was possible to compare the following:

1. desorbed and pristine CNT, to assess the impact of the purification from catalytic impurities,

2. desorbed and functionalized CNT, to evaluate the biological impact of surface acid groups. 


\section{EXPERIMENTAL PROCEDURES}

\section{Carbon nanotube treatments}

Two types of MWCNT were used: small and non-purified MWCNT (pristine: sCNT, functionalized: sCNTf, and desorbed: sCNTd) versus bigger ones previously annealed at $2600^{\circ} \mathrm{C}$ thus with few impurities and structural defects (pristine: bCNT, functionalized: bCNTf and desorbed: bCNTd). An extended physicochemical characterization was conducted according to the ISO recommendation (ISO International Organization for Standardization 2012). sCNT (NC7000, Nanocyl, Sambreville, Belgium) and bCNT (Nano Carbon Technologies Co., Tokyo, Japan) have diameters of $9.5 \mathrm{~nm}$ and 40-80 nm respectively according to the manufacturers, and lengths of $1.5 \mu \mathrm{m}$ and $2-20 \mu \mathrm{m}$ (from 250 measurements by optical microscopy). The annealing treatment undergone by the big CNT has reduced the level of catalytic impurities and structural defaults. A preliminary ultrasonic treatment was thus applied to the pristine bCNT to create reactive sites. Acid functionalization has been conducted after the optimization of a well-documented protocol (Ang et al. 2000; Rosca et al. 2005; Jain et al. 2011; Chen et al. 2012).

Preliminary treatment of pristine big CNT: 30\% intensity was applied using a microprobe on a $100 \mathrm{mg}$ bCNT /10 mL MQ water (Synergy 185, Millipore) suspension during $9 \mathrm{~h}(30 \%$, 3mm probe, Branson Sonifier S-450D).

Acid functionalization: following oxidation by refluxing in a solution of nitric and sulfuric acids (3:1 $\mathrm{v} / \mathrm{v}, 6 \mathrm{~h}$ for $\mathrm{sCNT}, 24 \mathrm{~h}$ for bCNT), functionalized CNT were filtered $(0.025 \mu \mathrm{m}$ MF-Millipore Membrane) and rinsed until the $\mathrm{pH}$ reached 5. The obtained functionalized CNT were dried into an oven at $100^{\circ} \mathrm{C}$ for $18 \mathrm{~h}$.

Desorption: A thermal treatment to desorb surface acid groups was applied on half of the functionalized CNT using a vacuum furnace. The sample was heated at $20^{\circ} \mathrm{C} \cdot \mathrm{min}^{-1}$ until $850^{\circ} \mathrm{C}$, then let cooled down to ambient temperature.

\section{Physicochemical characterization}


Morphology and diameter were analyzed using field-emission scanning electron microscopy (FEGSEM, model Supra $55 \mathrm{VP}$, Zeiss) at a $2 \mathrm{kV}$. Samples were prepared by the deposition of a small quantity of CNT powder on a carbon-coated holey film, and coated with a $3 \mathrm{~nm}$ gold layer. Diameters were expressed as the average value of 100 measurements. The same procedure was repeated 3 times using ImageJ software. Structural defects were studied using Raman spectroscopy (XploRA, Horiba Scientific, laser at $532 \mathrm{~nm}$ ). For each CNT type a spectrum was realized between 1000 and $2000 \mathrm{~cm}^{-1}$ using a network at $2400 \mathrm{~T}$. The specific surface areas $\left(\mathrm{SSA}, \mathrm{m}^{2} \cdot \mathrm{g}^{-1}\right)$ were determined by $\mathrm{N}_{2}$ adsorption at $77 \mathrm{~K}$ after out-gassing for $4 \mathrm{~h}$ at $110^{\circ} \mathrm{C}$ (Micromeritics ASAP 2000) using the Brunauer-Emmet-Teller (BET) method. The amount of metallic catalytic impurities was assessed by inductively coupled plasma atomic emission spectroscopy (ICP-AES).

Identification of the acid groups resulting from the functionalization was undergone by means of thermal desorption spectroscopy (TDS) and X-ray photoelectron spectroscopy (XPS). For TDS, $10 \mathrm{mg}$ of $\mathrm{CNT}$ powder were heated under vacuum at a heating rate of $20^{\circ} \mathrm{C} \cdot \mathrm{min}^{-1}$ until $850^{\circ} \mathrm{C}$. Two turbomolecular pumps ensure a vacuum less than $10^{-2} \mathrm{~Pa}$. A mass spectrometer (Balzers QMG 112 quadrupole) collected and analyzed the volatilized elements. XPS was used to determine the Oxygen atomic percentage (with $20 \%$ incertitude Thermo VG Thetaprobe, monochromatized Al K $\alpha$ source, $400 \mu$ m width analyzed, $1.3 \mathrm{x}$ $10^{-7} \mathrm{~Pa}$ of residual pressure). Samples were prepared by the sonication of a $30 \mu \mathrm{g} \cdot \mathrm{mL}^{-1} \mathrm{CNT}$ suspension in ethanol ( $5 \mathrm{~min}, 30 \%, 3 \mathrm{~mm}$ probe). One drop was deposited and dried on a $1 \mathrm{~cm}^{2}$ silicon wafer previously covered by a $5 \mathrm{~nm}$ gold layer to avoid $\mathrm{O}$ contribution from the substrate. The spectra were corrected for Shirley-type backgrounds. Automatic search of the peak positions were conducted from the fixed C1s peak at $284.5 \mathrm{eV}$. Atomic percentages were calculated from the peak areas and given sensitivity factors. Zeta potentials were measured using a Zetasizer Nano ZS (Malvern Instruments) and $30 \mu \mathrm{g} \cdot \mathrm{mL}^{-1} \mathrm{CNT}$ suspensions in MQ water prepared by sonication (5 to $15 \mathrm{~min}, 30 \%, 3 \mathrm{~mm}$ probe, Branson Sonifier).

\section{In vitro toxicity assessment}

Typical concentrations of 30,60 , and $120 \mu \mathrm{g} \cdot \mathrm{mL}^{-1}$ were used for the toxicity assays. Moreover, a 240 $\mu \mathrm{g} . \mathrm{mL}^{-1}$ and a $15 \mu \mathrm{g} \cdot \mathrm{mL}^{-1}$ concentration were also investigated, respectively for the big and small CNT, 
to obtain a comparable dose in surface. The highest concentrations of CNT were dispersed in culture medium: Dulbecco's Modified Eagle's Medium (DMEM, Invitrogen) complemented with $10 \%$ of fetal calf serum (FCS, Invitrogen), $1 \%$ penicillin-streptomycin (penicillin 10,000 U.mL ${ }^{-1}$, streptomycin 10 mg.mL $L^{-1}$, Sigma-Aldrich). A sonication was carried out until the complete dispersion of the suspension (5-30 min, 30\%, $3 \mathrm{~mm}$ probe, Branson Sonifier S-450D). The dispersion and suspension stability were established by measuring zeta potential and particle size distribution by means of the light scattering technique (Zetasier Nano ZS, see IX). After dilutions, the suspensions were kept at $4{ }^{\circ} \mathrm{C}$ and used in the following $48 \mathrm{~h}$. Toxicity assays were carried out on a RAW 264.7 cell line, provided by ATCC Cell Biology Collection (Promochem LGC) and derived from mice peritoneal macrophages transformed by the AMLV (Albeson Murine Leukemia Virus). Cells were cultured in complemented DMEM and incubated at $37^{\circ} \mathrm{C}$ under a $5 \%$ carbon dioxide humidified atmosphere.

\subsection{Oxidative stress}

Acute oxidative stress was estimated by measuring the intracellular reactive oxygen species (ROS) level using the OxiSelect ${ }^{\mathrm{TM}}$ Intracellular ROS Assay Kit (Cell Biolabs). Cells were allowed to adhere for $4 \mathrm{~h}$ in a black 96 well plate (seeded at $2 \times 10^{6}$ cells/well). A $1 \mathrm{~h}$ pre-treatment with the cell-permeant $2^{\prime} 7^{\prime}$ dichlorodihydrofluorescein $\left(\mathrm{H}_{2}\right.$ DCF-DA) was carried out before a short 90 min incubation with the CNT. The fluorescence intensities were read at $480 \mathrm{~nm}$ excitation and $530 \mathrm{~nm}$ emission (Fluoroskan Ascent, Thermo scientific). The results where then corrected for bias thanks to acellular standard curves: experiments were carried out to measure the variations between the fluorescence obtained for $0,10,100$, $1000 \mathrm{nM}$ standard curve of the fluorescent probe DCF (2',7'-dichlorodihydrofluorescein) in complemented medium with and without CNT. Corrections were calculated for each CNT type and each dose (Online Resource Figure S5 and Table S1).

\subsection{Pro-inflammatory response}

Tumor Necrosis Factor alpha (TNF- $\alpha$ ) production represents the appropriate cytokine indicator of the pro-inflammatory response for macrophage cells. After $24 \mathrm{~h}$ incubation with CNT in a 96 well plate (seeded at 100,000 cells/well), TNF- $\alpha$ release was assessed using a commercial enzyme-linked 
immunosorbent assay (ELISA) kit (Quantikine ${ }^{\circledR}$ Mouse TNF- $\alpha$ /TNFSF1A Immunoassay, R\&D systems). The optical density was determined according to the manufacturer's instructions, using a microplate reader (Multiskan GO, Thermo Scientific) at $450 \mathrm{~nm}$. A standard curve was established and results were expressed in pg.mL $\mathrm{mL}^{-1}$ of TNF- $\alpha$.

\subsection{Cytotoxicity}

Cell viability was evaluated by quantifying Lactate dehydrogenase (LDH) released in culture supernatant from cells with damaged membranes. After $24 \mathrm{~h}$ incubation with CNT in a 96-well plate (seeded at 100,000 cells/well), the CytoTox-96® Non-radioactive Cytotoxicity Assay (Promega) was used according to the manufacturer's instructions. Detection was performed using a microplate reader (Multiskan GO, Thermo Scientific) at $450 \mathrm{~nm}$. The activity of the released LDH was reported as a percentage of the total cellular LDH (measured after the complete lysis of control cells).

\subsection{Statistical analysis}

Results were expressed as the average of three independent experiments each carried out in triplicates, with standard errors of the mean value. Statistical significance was declared when $\mathrm{p}<0.05$ using a Student test (Rakotomalala 2005).

\section{RESULTS}

\section{Physicochemical characterization of carbon nanotubes}

Small and big CNT exhibited very different morphologies as shown by the FEG-SEM in Figure 1. Small CNT were named after their thin diameters of $9.5 \mathrm{~nm}$ according to the manufacturer, $23 \pm 4 \mathrm{~nm}$ according to FEG-SEM measurements, and short lengths of $1.5 \mu \mathrm{m}$ according to the manufacturer. Big CNT exhibited larger dimensions with diameters of $40-80 \mathrm{~nm}$ according to the manufacturers, $91 \pm 29 \mathrm{~nm}$ according to FEG-SEM measurements, and were longer with lengths reaching 2 to $20 \mu \mathrm{m}$ according to optical microscopy measurements. Small CNT appeared thin and curved, while big CNT were thick and straight due to their few amount of structural defects. As proposed by Lu et al. (Lu et al. 1996) bCNT first underwent an optimized $9 \mathrm{~h}$ ultrasonic treatment to create reactive sites for the acid functionalization with no significant effect on their diameter. After functionalization, a slight increase in carbonaceous debris 
was observed for both CNT types. Physicochemical features are presented in Table 1. Acid attack of the first graphene walls reduced the diameters by up to $7 \mathrm{~nm}$ for the small CNT and $15 \mathrm{~nm}$ for the big CNT. The entanglement of the tubes did unfortunately not allow to confirm the declared length for small CNT by FEG-SEM observations. No difference in length was detected by optical microscopy for big CNT after functionalization and desorption, but the technique remained imprecise. Likewise, the degree of structural defects rose for both CNT types after functionalization as revealed by the intensity of the D to G-band ratio from the Raman spectra (Online Resource Figure S1 and Figure S2). The diameters and the degree of structural defects remained close after thermal desorption of the surface acid groups. Specific surface areas were decreased of around $10 \%$ after functionalization according to the B.E.T. data.
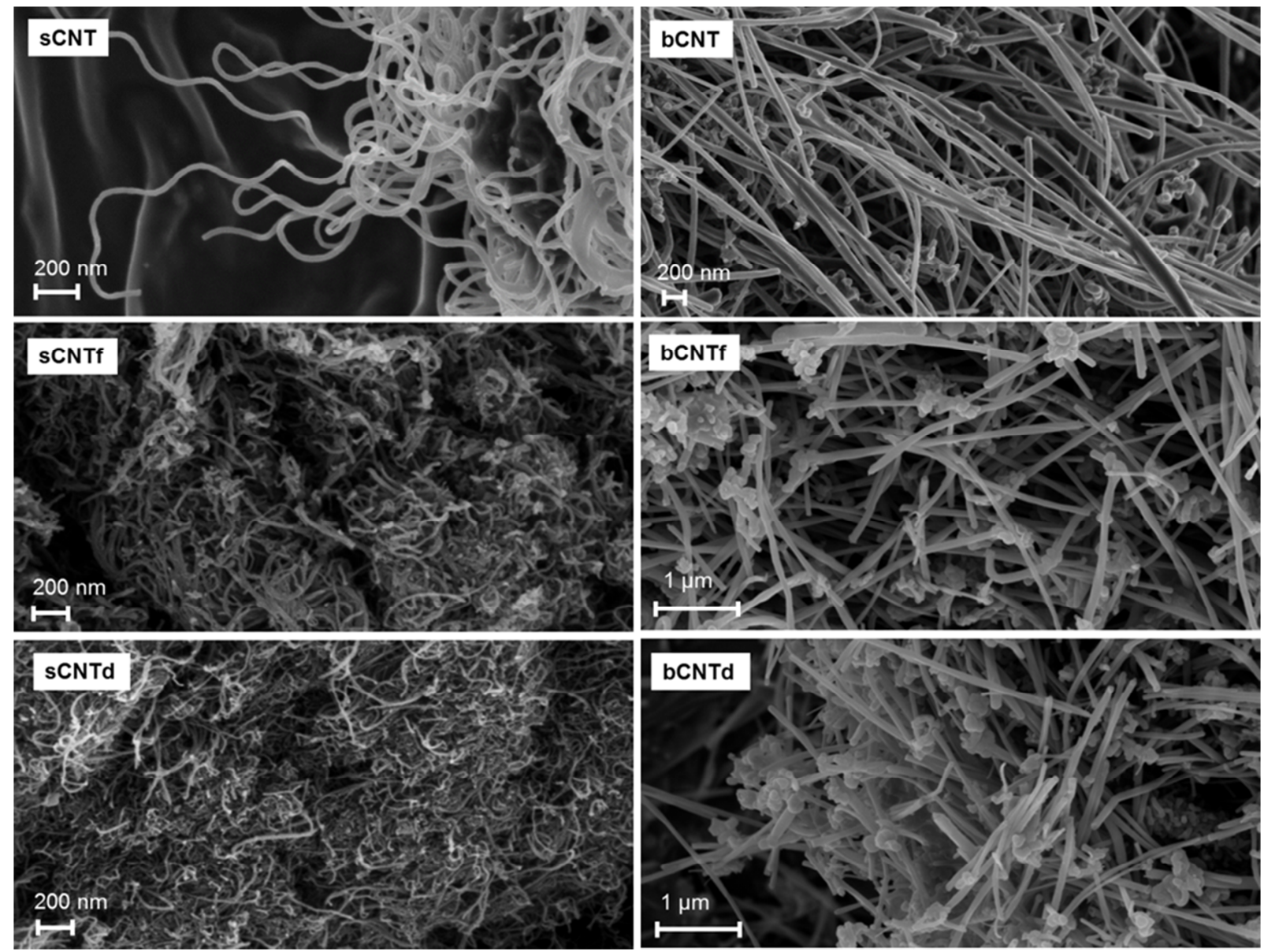
Figure 1. FEG-SEM images of small carbon nanotubes pristine (sCNT), functionalized (sCNTf), and desorbed by thermal treatment after functionalization ( $\mathrm{sCNTd}$ ), as well as big carbon nanotubes pristine (bCNT), functionalized (bCNTf) and desorbed (bCNTd).

Table 1. Physicochemical characteristics of the six carbon nanotubes.

\begin{tabular}{|c|c|c|c|c|c|c|}
\hline Sample & sCNT & sCNTf & sCNTd & bCNT & bCNTf & bCNTd \\
\hline Diameter (nm) & $23 \pm 4$ & $16 \pm 5$ & $15 \pm 4$ & $91 \pm 29$ & $76 \pm 21$ & $81 \pm 21$ \\
\hline $\begin{array}{l}\text { Structural } \\
\text { disorder (Id/Ig) }\end{array}$ & 0.82 & 1.83 & 1.76 & 0.24 & 0.35 & 0.35 \\
\hline $\operatorname{SSA}\left(m^{2} \cdot g^{-1}\right)_{A}$ & $317 \pm 2$ & $279 \pm 1$ & $335 \pm 2$ & $21.5 \pm 0.1$ & $19.0 \pm 0.4$ & $22.1 \pm 0.4$ \\
\hline $\begin{array}{l}\text { Catalytic } \\
\text { impurities } \\
\text { (wt.\%) }\end{array}$ & $\begin{array}{l}\text { Fe } 0.15 \\
\text { Al } 4.83 \\
\text { Co } 0.13\end{array}$ & $\begin{array}{l}\text { Fe } 0.05 \\
\text { Al } 0.03 \\
\text { Co } 0.02\end{array}$ & not-tested & $\begin{array}{l}\text { Fe } 0.51 \\
\text { Al } 0.01 \\
\text { Co } 0.00\end{array}$ & $\begin{array}{l}\text { Fe } 0.01 \\
\text { Al } 0.01 \\
\text { Co } 0.00\end{array}$ & not-tested \\
\hline $\mathbf{O}($ atomic \%) & 2 & 13 & I & 3 & 14 & 5 \\
\hline $\begin{array}{ll}\text { Zeta } & \text { potential } \\
(\mathbf{m V}) & \end{array}$ & $-9 \pm 8$ & $-48 \pm 2$ & $-19 \pm 2$ & $-23 \pm 12$ & $-41 \pm 7$ & $-1.29 \pm 13$ \\
\hline $\begin{array}{l}\text { Isoelectric point } \\
(\mathrm{pH})\end{array}$ & $\begin{array}{l}4.25 \quad \pm \\
0.86\end{array}$ & $<1.5$ & $3.51 \pm 0.13$ & $3.00 \pm 0.07$ & $1.79 \pm 0.13$ & $4.01 \pm 0.30$ \\
\hline $\begin{array}{l}\text { Representation } \\
\text { (Melchor and } \\
\text { Dobado 2004) }\end{array}$ & 80 & 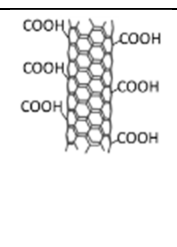 & $g^{\circ}$ & $\begin{array}{r}8 \\
30 \\
8 \\
8\end{array}$ & $\begin{array}{ll}\mathrm{COOH} & \mathrm{coOH} \\
\mathrm{CoOH} & \mathrm{coOH} \\
\mathrm{coOH} & \mathrm{coOH}\end{array}$ & $8^{2}$ \\
\hline
\end{tabular}

[A]: specific surface area. /: the measure could not be determined

ICP-AES evidenced high amounts of catalytic impurities for sCNT (4.8 wt.\% Al and more than 0.1 wt.\% Fe and $\mathrm{Co}$ ) which fell under 0.05 wt.\% after acid functionalization. Annealed bCNT contained only 0.5 wt. $\% \mathrm{Fe}$ and $0.01 \mathrm{wt} . \%$ after functionalization. 
Thermal desorption spectroscopy gave qualitative measurements of $\mathrm{CO}$ and $\mathrm{CO}_{2}$ during heating under vacuum of CNT. While sCNT and sCNTd exhibited very similar spectra with almost no gas desorption, two main peaks of sCNTf were identified as resulting from the desorption of $\mathrm{CO}$ and $\mathrm{CO}_{2}$ from the acid groups (Figure 2). It is consistent with Boehm (2002) which studied the desorption of surface groups from acid functionalization, and stated that desorbed $\mathrm{CO}_{2}$ are generally assumed to derive from carboxyl groups and CO from hydroxyl and ether-type oxygen. Big CNT showed similar trends with lower intensities of $\mathrm{CO}$ and $\mathrm{CO}_{2}$ peaks (Online Resource Figure S3). As expected, because of the high temperature treatment which decreased microstructural defects, bCNT and bCNTd are more stable in temperature respect to sCNT and sCNTd (Figure 2).
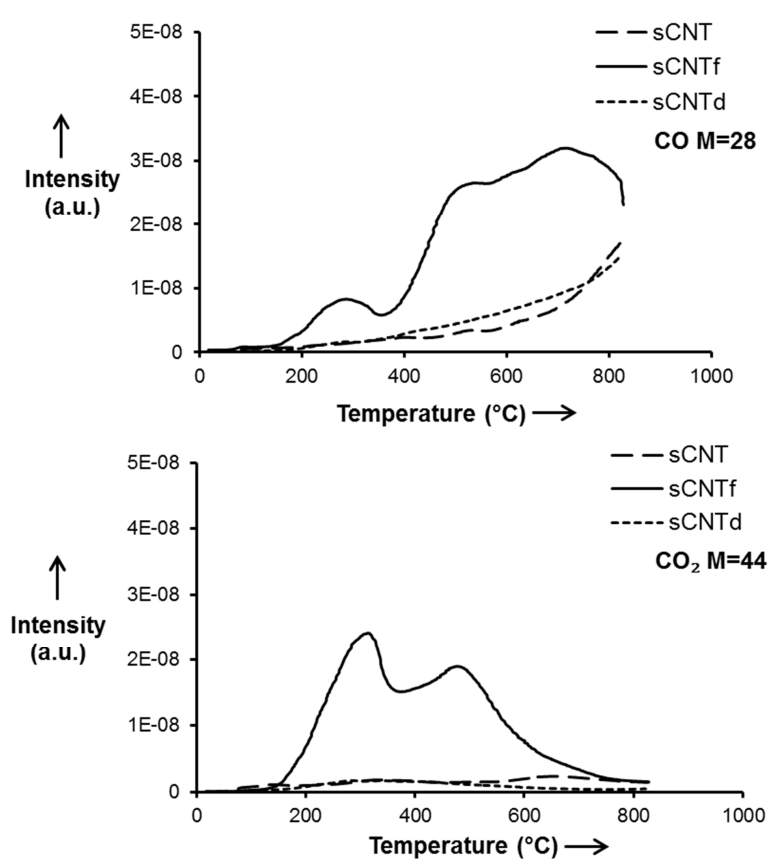

Figure 2. Thermal desorption of the small $\mathrm{CNT}, \mathrm{CO}$ and $\mathrm{CO}_{2}$ release. sCNT: small carbon nanotubes pristine, sCNTf: functionalized, and sCNTd: desorbed.

First, general XPS spectra were analyzed for the six samples. Three main peaks were identified: the $\mathrm{C} 1 \mathrm{~s}$ peak at $284.5 \mathrm{eV}$, the $\mathrm{O} 1 \mathrm{~s}$ peak at $533 \mathrm{eV}$, and the Au4f peaks from the substrate at 84 and $87.5 \mathrm{eV}$. The absence of contribution from the $\mathrm{SiO}_{2}$ substrate (no signal from the $\mathrm{Si} 2 \mathrm{p}$ peak) and from the air contamination were verified. A more detailed spectrum was realized for each of the four peaks. Oxygen 
atomic percentage rose after functionalization but came back close to the pristine ones for the desorbed bCNTd.

Charged surface acid groups linked by CNT functionalization can be assessed by the measurement of the zeta potential $(\zeta)$ and of the isoelectric point $(\mathrm{pI}) . \zeta$ in water decreased from -9 to $-48 \mathrm{mV}$ for sCNT and sCNTf, and from -23 to $-41 \mathrm{mV}$ for bCNT and bCNTf respectively. $\mathrm{pI}$ of functionalized CNT were lower than 1.8, but have been detected over 3.0 for pristine and desorbed CNT.

\section{In vitro cellular responses}

The biological activity of the six CNT was assessed using a murine macrophage cell line (RAW 264.7). Microscopic observations revealed interactions between CNT and cells with phagocytosis of small CNT (Online Resource Figure S4). Three different cellular and molecular parameters were evaluated: LDH release, assessing cell membrane integrity and thus the cytotoxicity, TNF- $\alpha$ production, indicating the pro-inflammatory response, and intracellular ROS production, directly related to oxidative stress. The cells were incubated with three doses of CNT within the range of in vitro concentrations commonly used (30, 60, $120 \mu \mathrm{g} . \mathrm{mL}^{-1}$ or 7.5-30 $\mu \mathrm{g} . \mathrm{cm}^{-2}$ ) (Fraczek-Szczypta et al. 2012; Dong et al. 2012; Wang et al. 2012; Zhang et al. 2012). These concentrations correspond to those of Vietti et al. (2013) study, even though they stated that relevant concentrations regarding the first occupational exposures studies stand around $0.025-0.2 \mu \mathrm{g} . \mathrm{cm}^{-2}$ to simulate a two months exposure. But because lung deposition is irregular in vivo and because in vitro studies are looking at acute toxicity with a maximum of 24 hours exposure, while not $100 \%$ CNT will deposit on the cells, they considered the used concentration range as pertinent. Moreover as big CNT have a 15 times smaller specific area, a $240 \mu \mathrm{g} \cdot \mathrm{mL}^{-1}$ and a $15 \mu \mathrm{g} \cdot \mathrm{mL}^{-1}$ concentrations were added respectively for the big and small CNT for a comparable dose in surface.

\subsection{Oxidative stress}

ROS production was evaluated by a fluorimetric method which was strongly biased by the presence of carbon nanotubes in the culture supernatant as it has been demonstrated for techniques for other toxicological outcomes such as MTT assay (Wörle-Knirsch et al. 2006; Casey et al. 2007; Belyanskaya et al. 2007; Shvedova et al. 2009). Corrections based on acellular standard curves were applied (see Online 
Resource Figure S5 and Table S1). At high doses of sCNT ROS levels were respectively twice and more than three times higher than for the positive control (cells incubated with $1 \mathrm{mM}$ of $\mathrm{H}_{2} \mathrm{O}_{2}$, Figure 3). However, after functionalization and desorption, the levels were reduced to just half of the initial values. No significant change was observed between sCNTf and sCNTd. Values for big CNT were not significantly different from the negative control (data not shown).

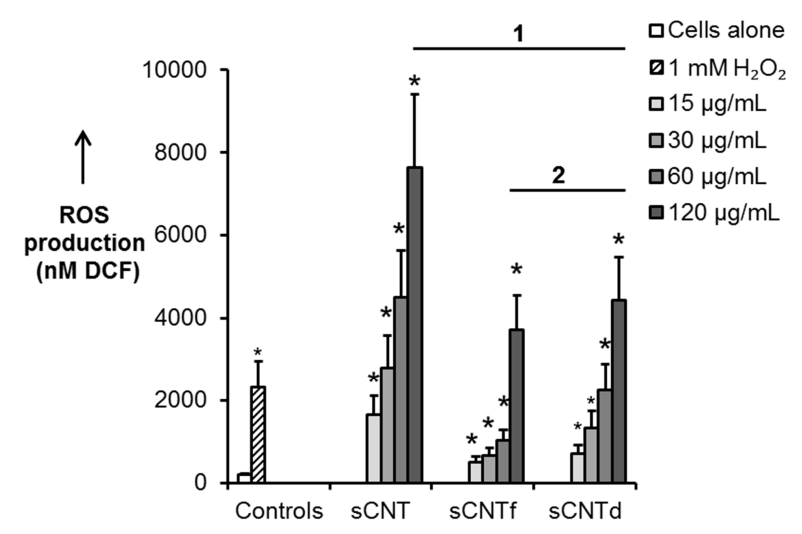

Figure 3. Impact of the purification (1) and absence of impact of surface acid groups (2) of the small CNT on the oxidative stress determined by ROS production after a 90 min exposure $(n=3, * p<0.05)$. Results are expressed in $\mathrm{nM}$ of 2',7'-dichlorohidrofluorescein (DCF) after correction for CNT absorption. sCNT: small carbon nanotubes pristine, sCNTf: functionalized, and sCNTd: desorbed.

\subsection{Pro-inflammatory response}

TNF- $\alpha$ production was enhanced in a dose-dependent way by any dose of sCNTf but only by high doses of sCNT (Figure 4). Conversely sCNTd induced no significant response. Any dose of bCNT significantly induced TNF- $\alpha$ production in a dose-dependent manner (Figure 5). bCNTd showed no significant TNF- $\alpha$ production except at the highest concentration, showing a crucial reduction of the proinflammatory response for concentrations under $240 \mu \mathrm{g} \cdot \mathrm{mL}^{-1}$. bCNTf induced a significant response from $120 \mu \mathrm{g} \cdot \mathrm{mL}^{-1}$ at significantly higher levels than bCNTd. 


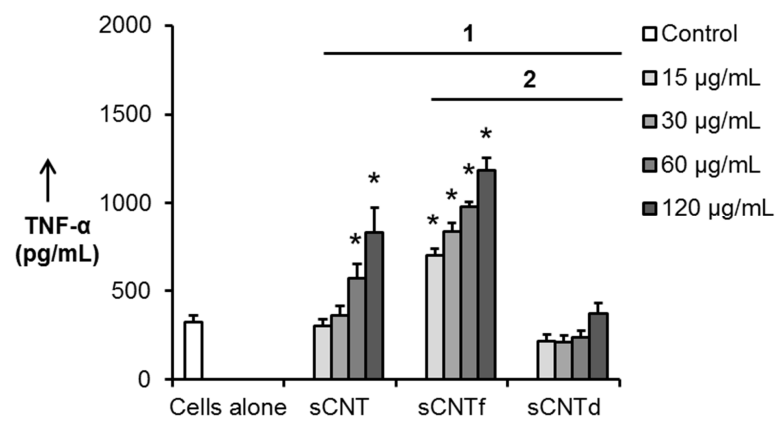

Figure 4. Impact of the purification (1) and of surface acid groups (2) of the small CNT on the proinflammatory response determined by TNF- $\alpha$ production after a $24 \mathrm{~h}$ exposure $(\mathrm{n}=3, *-\mathrm{p}<0.05)$. sCNT: small carbon nanotubes pristine, sCNTf: functionalized, and sCNTd: desorbed.

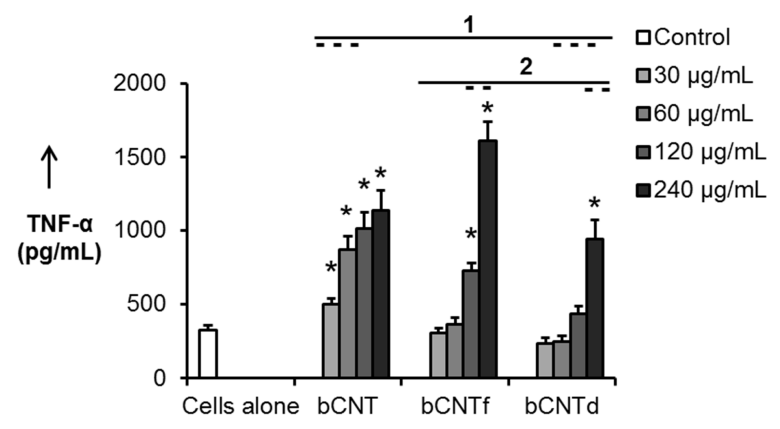

Figure 5. Impact of the purification (1) and of surface acid groups (2) of the big CNT on the proinflammatory response determined by TNF- $\alpha$ production after a $24 \mathrm{~h}$ exposure $(n=3, *-p<0.05)$. bCNT: big carbon nanotubes pristine, bCNTf: functionalized, and bCNTd: desorbed.

\subsection{Cytotoxicity}

Cytotoxicity was only significant at the highest dose of sCNT with 50\% released LDH (Figure 6). After functionalization and following desorption, no significant cytotoxicity was observed. Nevertheless, at the highest dose of sCNTd, LDH level tended to a lower value compared to sCNTf. No significant LDH release was observed after incubation of the cells with bCNT (Figure 7). However, after functionalization and following desorption, LDH release increased significantly reaching around $60 \%$ for bCNTd. 


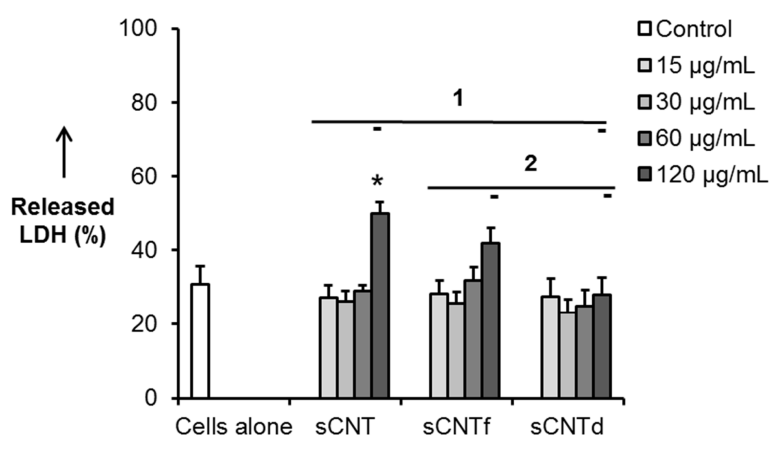

Figure 6. Impact of the purification (1) and of surface acid groups (2) of small CNT on the cytotoxicity determined by LDH release after a $24 \mathrm{~h}$ exposure reported to that of total cellular LDH measured after the lysis of negative control cells $(\mathrm{n}=3, *-\mathrm{p}<0.05)$. sCNT: small carbon nanotubes pristine, sCNTf: functionalized, and sCNTd: desorbed.

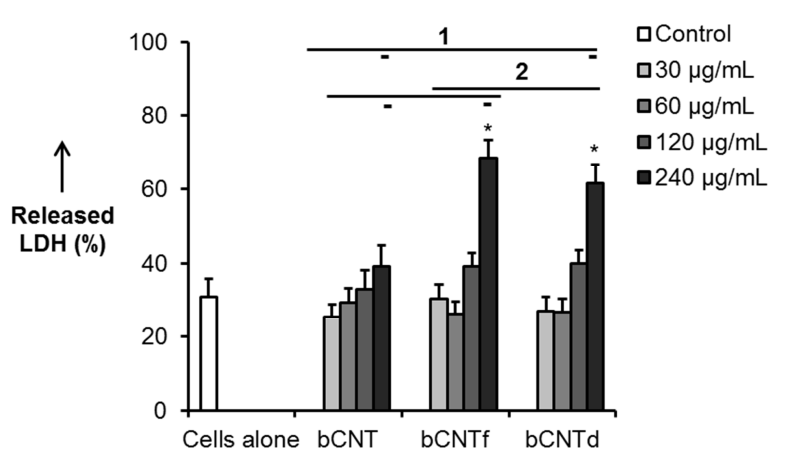

Figure 7. Impact of acid functionalization of big CNT on the cytotoxicity determined by LDH release after a $24 \mathrm{~h}$ exposure reported to that of total cellular LDH measured after the lysis of negative control cells $(n=3, *-p<0.05,1$ : potential impact of the purification and 2: of the surface acid groups). bCNT: big carbon nanotubes pristine, bCNTf: functionalized, and bCNTd: desorbed.

\section{DISCUSSION}

\section{Physicochemical characterization}

The two CNT types, small or big, exhibited very dissimilar features in size, specific surface area, and in the amount of structural defects and catalytic impurities due to the annealing treatment of bCNT (Kim et 
al. 2005; Musso et al. 2009). However, the aim of this study was not to focus on the comparison between big and small CNT but to highlight shared trends in the biological impact of acid functionalization and to discriminate the influence of surface acid groups from that of the purification from catalytic impurities (see summary in Table 2). Even though a complete exclusion of the other parameters cannot be guaranteed, when comparing pristine and functionalized CNT, as CNT physicochemical assessment led to conclude that surface acid groups and metallic impurities are the main parameters altered by an acid functionalization. Aside from the purification and the functionalized groups, the acid treatment modified the CNT structure by decreasing their diameters and by increasing their structural defects. As Hu et al. (Hu et al. 2003) observed in their work, thinning down CNT diameters and increase in debris were observed on SEM pictures for both CNT types after functionalization. Raman Id/Ig ratio confirmed the formation of structural defects after functionalization, at very low levels for big CNT due to the annealing treatment. These outcomes remained unchanged after desorption of the surface acid groups, thus the comparison between functionalized and desorbed CNT was not influenced by these parameters, but they have to be kept in mind when comparing pristine and desorbed ones. SSA remained at comparable levels after acid treatment following by desorption. The $10 \%$ decrease observed directly after functionalization may be due to the steric effect of the acid groups, while the minor increase after desorption may be due to the reduction of aggregate amount (Petersen and Henry 2012).

The presence of surface acid groups resulting from acid functionalization was confirmed by TDS, by XPS and by the decrease of pI determined from zeta potential measurements. Moreover, the "defunctionalization" was validated by thermal desorption techniques as a method to eliminate most of the surface acid groups. The difficulty to functionalize the annealed big CNT with few structural defects was evidenced by a lower amount of surface acid groups and by lower TDS peak intensities. It can also been explained by the large diameter of the bCNT and weak reactivity of its surface. Indeed, $\mathrm{C} \mathrm{sp}{ }^{2}$ constituting CNT are forced to maintain a deformed orbital geometry due to the curvature of the tube. This phenomenon is called pyramidalization. The lower the curvature is (i.e. the higher diameter is), the lower the pyramidalization angle and the reactivity of CNT are (Chen et al. 2003). Atomic concentrations 
obtained from XPS measurements are semi-quantitative and confirmed the qualitative TDS measurements. Both techniques however indicate that oxidation occurred but cannot specify the nature of the functional groups. Moreover, the presence of surface acid groups enhanced the stability of CNT suspensions in water. Unstable dispersions are characterized by a zeta potential between $-30 \mathrm{mV}$ and +30 $\mathrm{mV}$, and they were found out of this range only for functionalized CNT. However zeta potentials can vary a lot according to $\mathrm{pH}$ and ionic strength. A pH titration was thus realized to determine the isoelectric point, an independent parameter which lastly confirmed that functionalization and desorption processes were completed.

\section{In vitro cellular response}

Metal impurities (especially $\mathrm{Fe}$ ) have been extensively linked with oxidative stress enhancement, due to their involvement in the Fenton reaction (Carter et al. 1997; Pulskamp et al. 2007; Ge et al. 2012). The absence of any significant ROS production for big CNT is thus consistent with their low amount of impurities. Likewise, the critical decline of ROS production of the small CNT after acid functionalization could be imputed to the purification from catalytic impurities, as no significant difference was seen after desorption of the surface acid groups (see summary in table 2). Surprisingly they have been little study on the impact of acid functionalization on oxidative stress. The results of this study are consistent with those of Jain et al. (2011) which found in vivo a decrease in oxidative stress after acid functionalization which was not linked to the degree of functionalization. To our knowledge only one other study examined the impact of a thermal treatment $\left(600^{\circ} \mathrm{C} 4 \mathrm{~h}\right.$ under $\left.\mathrm{N}_{2}\right)$ after acid functionalization. Zhang et al. work (2011) concluded that functionalized MWCNT induced more oxidative stress on HeLa cells compared to the thermally treated ones. No comparison was done with pristine CNT and no further discussion was made about the potential role of surface acid groups. Moreover, a different cell line has been used (human cervix adenocarcinoma) which could explain the difference in toxicity mechanism.

Table 2. Summary of the impact of CNT acid functionalization on the biological response. $\nearrow$ : increase, $\rightarrow$ : no significant change, or $\downarrow$ : decrease after purification or addition of surface acid groups. 


\begin{tabular}{|l|l|l|l|}
\hline & $\begin{array}{l}\text { Oxidative } \\
\text { stress }\end{array}$ & $\begin{array}{l}\text { Pro-inflammatory } \\
\text { response }\end{array}$ & Cytotoxicity \\
\hline Purification & $\searrow$ & $\searrow$ & $\searrow$ \\
sCNT $\leftrightarrow$ sCNTd & $\rightarrow$ & $\searrow$ & Observed $\nearrow$ but supposed $\searrow$ \\
bCNT $\leftrightarrow$ bCNTd & $\rightarrow$ & $\nearrow$ & $\rightarrow$ \\
Surface acid groups & $\rightarrow$ & $\nearrow$ if $>\mathrm{t}^{[\mathrm{a}]}$ & $\begin{array}{l}\text { Observed } \rightarrow \text { but supposed } \nearrow \text { if } \\
\text { sCNTd } \leftrightarrow \text { sCNTf }\end{array}$ \\
bCNTd $\leftrightarrow$ bCNTf & & \\
\hline
\end{tabular}

[a] threshold of surface acid groups dependent of CNT types

The purification of catalytic impurities is also thought to be involved in the decrease of the proinflammatory response. Surface acid groups seemed to trigger the TNF- $\alpha$ production when present in a concentration higher to a threshold determined by the CNT type (bCNTf increased TNF- $\alpha$ production only at the highest concentrations). The opposite impacts of purification and of surface acid groups were underlined. They allow a better understanding of the conflicting results of the literature regarding the proinflammatory response, as enhancement (Dong et al. 2012; Wang et al. 2012) or decrease (Jain et al. 2011) due to acid functionalization have both been observed. Zhang et al. (2011) did not assess the production of pro-inflammatory factors with their functionalized or thermally treated CNT, so this study cannot confirm our theory.

Regarding cytotoxicity, the same mechanism of decrease in toxicity by the removal of catalytic impurities is believed to occur. No significant LDH releases were observed after functionalization of the small CNT with or without high level of surface acid groups. At $120 \mu \mathrm{g} \cdot \mathrm{mL}^{-1} \mathrm{sCNTf}$ exhibited what could be a slight echo from the increase in the pro-inflammatory response, but the LDH release remained nonsignificant. A contradictory trend appeared to exist for big CNT. bCNT were not cytotoxic while bCNTf and bCNTd at $240 \mu \mathrm{g} \cdot \mathrm{mL}^{-1}$ induced LDH release which were not significantly different from one another. This suggested that purification but not surface acid groups were associated with an increase in 
cytotoxicity. However, according to our results it is rather believed that the impact of purification was not detectable due to the low amount of impurities. The significant increase in LDH release observed after functionalization could be attributed to the surface acid groups with a threshold-dependent mechanism explaining why LDH release remained significant after the desorption of part of the surface acid groups. For Zhang et al. (2011) after a thermal treatment removing the surface acid groups, the induced cytotoxicity was found lower than for just functionalized CNT. They suggested that surface acid groups do have an influence on cytotoxicity. Our hypothesis involving a threshold mechanism dependent on the CNT structure could explain the inconsistency in previous works. For several studies, acid functionalization tended to increase the cytotoxicity (Bottini et al. 2006; Dong et al. 2012; Wang et al. 2012; Fröhlich et al. 2012), while for others, it had no impact (Fraczek-Szczypta et al. 2012) or conversely decreased the cytotoxicity (Zhang et al. 2012; Lorena Montes-Fonseca et al. 2012).

The increased effect on TNF production and cytotoxicity of functionalized CNT with surface acid groups could be due to an increase of the bioactivity or higher reactivity of the functionalized surface. However, this could also be explained by the increased dispersibility of the CNT in the aqueous culture medium even though an optimized sonication tended to lower the difference. Cells could be exposed to a greater number of CNT structures with higher available surface area, which has been reported to enhance biological impacts (Wang et al. 2010). TNF- $\alpha$ and LDH results were also examined with doses expressed in surface calculated from the CNT specific surface area (Online Resource Figure S6 and Figure S7). Whatever the surface chemical property, the pro-inflammatory response and cytotoxicity after contact with the big CNT were globally higher than those triggered by the small CNT for equivalent mass or surface doses. This could be due to "frustrated phagocytosis" generated by these long and straight CNT (Brown et al. 2007; Tran et al. 2011; Gustavsson et al. 2012). Indeed, it has been reported that macrophages fail to fully engulf oversized CNT and try constantly to break them down instead. This "frustrated phagocytosis" has been shown to trigger inflammation, in addition to oxidative stress, genotoxicity and apoptosis. 
Furthermore the conclusions suggested in this study are based on in vitro tests. It is acknowledged that cell culture studies do not always reflect in vivo responses and by extension real-life exposure consequences. However, such studies can help identifying the basic mechanisms of the CNT biological reactivity and help industrials to understand these trends to design safer nanomaterials. 


\section{CONCLUSION}

In conclusion, the two main physicochemical effects of the acid functionalization of CNT can induce a Janus impact on in vitro cellular response. The CNT purification appeared to decrease the induction of oxidative stress, pro-inflammatory response and cytotoxicity. Conversely the surface acid groups seemed to increase the pro-inflammatory response and the cytotoxicity if exceeding a threshold dependent on the CNT type. Therefore, acid functionalization could increase the toxicity of CNT depending on their degree of catalytic impurities and of a threshold. This mechanism should be further investigated. The benefit-risk balance of an acid functionalization should be considered for future applications of CNT under a safer by design approach.

\section{ACKNOWLEDGMENT}

The authors would like to acknowledge the financial support of Saint-Etienne Métropole and the Conseil Général de la Loire. The authors would like to thank Yoann Garnier and Vincent Barnier from the structure and material center (EMSE) for their help regarding the XPS measurements.

\section{REFERENCES}

Ahmadzadeh Tofighy M, Mohammadi T (2012) Nitrate removal from water using functionalized carbon nanotube sheets. Chem Eng Res Des 90:1815-1822. doi: 10.1016/j.cherd.2012.04.001

Ang LM, Hor TSA, Xu GQ, et al. (2000) Decoration of activated carbon nanotubes with copper and nickel. Carbon 38:363-372. doi: 10.1016/S0008-6223(99)00112-8

Baughman RH, Zakhidov AA, Heer WA de (2002) Carbon Nanotubes--the Route Toward Applications. Science 297:787-792. doi: 10.1126/science.1060928

Belyanskaya L, Manser P, Spohn P, et al. (2007) The reliability and limits of the MTT reduction assay for carbon nanotubes-cell interaction. Carbon 45:2643-2648. doi: 10.1016/j.carbon.2007.08.010

Bianco A, Kostarelos K, Prato M (2005) Applications of carbon nanotubes in drug delivery. Curr Opin Chem Biol 9:674-679. doi: 10.1016/j.cbpa.2005.10.005

Bianco A, Kostarelos K, Prato M (2011) Making carbon nanotubes biocompatible and biodegradable. Chem Commun 47:10182-10188. doi: 10.1039/c1cc13011k 
Boehm HP (2002) Surface oxides on carbon and their analysis: a critical assessment. Carbon 40:145-149. doi: $10.1016 / S 0008-6223(01) 00165-8$

Bottini M, Bruckner S, Nika K, et al. (2006) Multi-walled carbon nanotubes induce T lymphocyte apoptosis. Toxicol Lett 160:121-126. doi: 10.1016/j.toxlet.2005.06.020

Brown DM, Kinloch IA, Bangert U, et al. (2007) An in vitro study of the potential of carbon nanotubes and nanofibres to induce inflammatory mediators and frustrated phagocytosis. Carbon 45:17431756. doi: 10.1016/j.carbon.2007.05.011

Carter JD, Ghio AJ, Samet JM, Devlin RB (1997) Cytokine Production by Human Airway Epithelial Cells after Exposure to an Air Pollution Particle Is Metal-Dependent. Toxicol Appl Pharmacol 146:180-188. doi: 10.1006/taap.1997.8254

Casey A, Herzog E, Davoren M, et al. (2007) Spectroscopic analysis confirms the interactions between single walled carbon nanotubes and various dyes commonly used to assess cytotoxicity. Carbon 45:1425-1432. doi: 10.1016/j.carbon.2007.03.033

Chen J, Chen Q, Ma Q (2012) Influence of surface functionalization via chemical oxidation on the properties of carbon nanotubes. J Colloid Interface Sci 370:32-38. doi: 10.1016/j.jcis.2011.12.073

Chen Z, Thiel W, Hirsch A (2003) Reactivity of the Convex and Concave Surfaces of Single-Walled Carbon Nanotubes (SWCNTs) towards Addition Reactions: Dependence on the Carbon-Atom Pyramidalization. ChemPhysChem 4:93-97. doi: 10.1002/cphc.200390015

Choi J-Y, Ramachandran G, Kandlikar M (2009) The Impact of Toxicity Testing Costs on Nanomaterial Regulation. Environ Sci Technol 43:3030-3034. doi: 10.1021/es802388s

De Volder MFL, Tawfick SH, Baughman RH, Hart AJ (2013) Carbon Nanotubes: Present and Future Commercial Applications. Science 339:535-539. doi: 10.1126/science.1222453

Dong P-X, Wan B, Guo L-H (2012) In vitro toxicity of acid-functionalized single-walled carbon nanotubes: Effects on murine macrophages and gene expression profiling. Nanotoxicology 6:288-303. doi: 10.3109/17435390.2011.573101

Fraczek-Szczypta A, Menaszek E, Syeda T, et al. (2012) Effect of MWCNT surface and chemical modification on in vitro cellular response. J Nanoparticle Res 14:1-14. doi: 10.1007/s11051-012$1181-1$

Fröhlich E, Meindl C, Höfler A, et al. (2012) Combination of small size and carboxyl functionalisation causes cytotoxicity of short carbon nanotubes. Nanotoxicology 1-14. doi: $10.3109 / 17435390.2012 .729274$

Ge C, Li Y, Yin J-J, et al. (2012) The contributions of metal impurities and tube structure to the toxicity of carbon nanotube materials. NPG Asia Mater 4:e32. doi: 10.1038/am.2012.60

Gustavsson P, Hedmer M, Rissler J (2012) Carbon nanotubes - Exposure, toxicology and protective measures in the work environment. Swedish Work Environment Authority (Arbetsmiljöverket) 
Gutiérrez-Praena D, Pichardo S, Sánchez E, et al. (2011) Influence of carboxylic acid functionalization on the cytotoxic effects induced by single wall carbon nanotubes on human endothelial cells (HUVEC). Toxicol In Vitro 25:1883-1888. doi: 10.1016/j.tiv.2011.05.027

Hu H, Zhao B, Itkis ME, Haddon RC (2003) Nitric acid purification of single-walled carbon nanotubes. J Phys Chem B 107:13838-13842. doi: 10.1021/jp035719i

Huang J, Ng AL, Piao Y, et al. (2013) Covalently Functionalized Double-Walled Carbon Nanotubes Combine High Sensitivity and Selectivity in the Electrical Detection of Small Molecules. J Am Chem Soc 135:2306-2312. doi: 10.1021/ja310844u

ISO - International Organization for Standardization (2012) ISO/TR 13014:2012 - Nanotechnologies -Guidance on physico-chemical characterization of engineered nanoscale materials for toxicologic assessment.

Jain S, Thakare VS, Das M, et al. (2011) Toxicity of Multiwalled Carbon Nanotubes with End Defects Critically Depends on Their Functionalization Density. Chem Res Toxicol 24:2028-2039. doi: $10.1021 / \mathrm{tx} 2003728$

Kagan VE, Konduru NV, Feng W, et al. (2010) Carbon nanotubes degraded by neutrophil myeloperoxidase induce less pulmonary inflammation. Nat Nanotechnol 5:354-359. doi: 10.1038/nnano.2010.44

Kayat J, Gajbhiye V, Tekade RK, Jain NK (2011) Pulmonary toxicity of carbon nanotubes: a systematic report. Nanomedicine Nanotechnol Biol Med 7:40-49. doi: 10.1016/j.nano.2010.06.008

Kim YA, Hayashi T, Endo M, et al. (2005) Synthesis and structural characterization of thin multi-walled carbon nanotubes with a partially facetted cross section by a floating reactant method. Carbon 43:2243-2250. doi: 10.1016/j.carbon.2005.03.039

Krug HF, Wick P (2011) Nanotoxicology: An Interdisciplinary Challenge. Angew Chem-Int Ed 50:12601278. doi: 10.1002/anie.201001037

Liu X, Hurt RH, Kane AB (2010) Biodurability of single-walled carbon nanotubes depends on surface functionalization. Carbon 48:1961-1969. doi: 10.1016/j.carbon.2010.02.002

Lorena Montes-Fonseca S, Orrantia-Borunda E, Aguilar-Elguezabal A, et al. (2012) Cytotoxicity of functionalized carbon nanotubes in J774A macrophages. Nanomedicine-Nanotechnol Biol Med 8:853-859. doi: 10.1016/j.nano.2011.10.002

Lu KL, Lago RM, Chen YK, et al. (1996) Mechanical damage of carbon nanotubes by ultrasound. Carbon 34:814-816. doi: 10.1016/0008-6223(96)89470-X

Melchor S, Dobado JA (2004) CoNTub: An Algorithm for Connecting Two Arbitrary Carbon Nanotubes. J Chem Inf Comput Sci 44:1639-1646. doi: 10.1021/ci049857w

Musso S, Tulliani J-M, Ferro G, Tagliaferro A (2009) Influence of carbon nanotubes structure on the mechanical behavior of cement composites. Compos Sci Technol 69:1985-1990. doi: 10.1016/j.compscitech.2009.05.002 
Petersen EJ, Henry TB (2012) Methodological considerations for testing the ecotoxicity of carbon nanotubes and fullerenes: Review. Environ Toxicol Chem 31:60-72. doi: 10.1002/etc.710

Pulskamp K, Diabaté S, Krug HF (2007) Carbon nanotubes show no sign of acute toxicity but induce intracellular reactive oxygen species in dependence on contaminants. Toxicol Lett 168:58-74. doi: $10.1016 /$ j.toxlet.2006.11.001

Rakotomalala R (2005) TANAGRA : un logiciel gratuit pour l'enseignement et la recherche. RNTI-E-3. pp 697-702

Rosca ID, Watari F, Uo M, Akasaka T (2005) Oxidation of multiwalled carbon nanotubes by nitric acid. Carbon 43:3124-3131. doi: 10.1016/j.carbon.2005.06.019

Schrurs F, Lison D (2012) Focusing the research effort. Nat Nanotechnol 7:546-548.

Shvedova AA, Kisin ER, Porter D, et al. (2009) Mechanisms of pulmonary toxicity and medical applications of carbon nanotubes: Two faces of Janus? Pharmacol Ther 121:192-204. doi: 10.1016/j.pharmthera.2008.10.009

Simon-Deckers A, Gouget B, Mayne-L'Hermite M, et al. (2008) In vitro investigation of oxide nanoparticle and carbon nanotube toxicity and intracellular accumulation in A549 human pneumocytes. Toxicology 253:137-146. doi: 10.1016/j.tox.2008.09.007

Singh S, Vardharajula S, Tiwari P, et al. (2012) Functionalized carbon nanotubes: biomedical applications. Int J Nanomedicine 5361. doi: 10.2147/IJN.S35832

Tran C, Tantra R, Donaldson K, et al. (2011) A hypothetical model for predicting the toxicity of high aspect ratio nanoparticles (HARN). J Nanoparticle Res 13:6683-6698. doi: 10.1007/s11051-011$0575-9$

Vietti G, Ibouraadaten S, Palmai-Pallag M, et al. (2013) Towards predicting the lung fibrogenic activity of nanomaterials: experimental validation of an in vitro fibroblast proliferation assay. Part Fibre Toxicol 10:52-52.

Wang X, Guo J, Chen T, et al. (2012) Multi-walled carbon nanotubes induce apoptosis via mitochondrial pathway and scavenger receptor. Toxicol. Vitro Int. J. Publ. Assoc. BIBRA 26:

Wang X, Xia T, Ntim SA, et al. (2010) Quantitative Techniques for Assessing and Controlling the Dispersion and Biological Effects of Multiwalled Carbon Nanotubes in Mammalian Tissue Culture Cells. Acs Nano 4:7241-7252. doi: 10.1021/nn102112b

Wörle-Knirsch JM, Pulskamp K, Krug HF (2006) Oops They Did It Again! Carbon Nanotubes Hoax Scientists in Viability Assays. Nano Lett 6:1261-1268. doi: 10.1021/n1060177c

Zhang T, Tang M, Kong L, et al. (2012) Comparison of cytotoxic and inflammatory responses of pristine and functionalized multi-walled carbon nanotubes in RAW 264.7 mouse macrophages. J Hazard Mater 219-220:203-212. doi: 10.1016/j.jhazmat.2012.03.079

Zhang X, Zhu Y, Li J, et al. (2011) Tuning the cellular uptake and cytotoxicity of carbon nanotubes by surface hydroxylation. J Nanoparticle Res 13:6941-6952. doi: 10.1007/s11051-011-0603-9 


\section{Supporting information}

Control of Carbon Nanotubes Biological Activity by Acid Functionalization:

Comprehensive Analysis of its Janus Impact on In Vitro Cellular Response

Agathe Figarol *, Jérémie Pourchez *, Delphine Boudard, Valérie Forest, Jean-Marc Tulliani, Jean-Pierre Lecompte, Michèle Cottier, Didier Bernache-Assollant, Philippe Grosseau

A. Figarol, P. Grosseau

Ecole Nationale Supérieure des Mines, SPIN-EMSE, CNRS: UMR 5307, LGF, Propice Department 158, Cours Fauriel, F-42023 Saint-Etienne, France

E-mail: figarol@emse.fr

A. Figarol, J. Pourchez, V. Forest, D. Bernache-Assollant Ecole Nationale Supérieure des Mines, CIS-EMSE, EA 4624, SFR IFRESIS, LINA, BioPi Department 158, Cours Fauriel, F-42023 Saint-Etienne, France

E-mail : pourchez@emse.fr

D. Boudard, M. Cottier

Université Jean Monnet Saint-Etienne, EA 4624, SFR IFRESIS, LINA,

Faculté de Médecine Jacques Lisfranc

15, rue Ambroise Paré, F-42023 Saint-Etienne, France

CHU de Saint-Etienne,

F-42055, Saint-Etienne, France

J.-M. Tulliani

Politecnico di Torino, Department of Applied Science and Technology, 
10129 Torino, Italy

J.-P. Lecompte

SPCTS Centre Européen de la Céramique CNRS: UMR 7315,

F-87068 Limoges, France

* Correspondence to: figarol@gmail.com +334 77420213 or pourchez@gmail.com +334 77420180

\section{RAMAN SPECTRA}

Raman spectra exhibited two main bands for both carbon nanotubes (CNT) types. They are called the D-band $\left(1340 \mathrm{~cm}^{-1}\right)$ and the G-band $\left(1570 \mathrm{~cm}^{-1}\right)$ (Figure S1 and Figure S2). Two overtone peaks were also observed $\left(>2500 \mathrm{~cm}^{-1}\right)$.

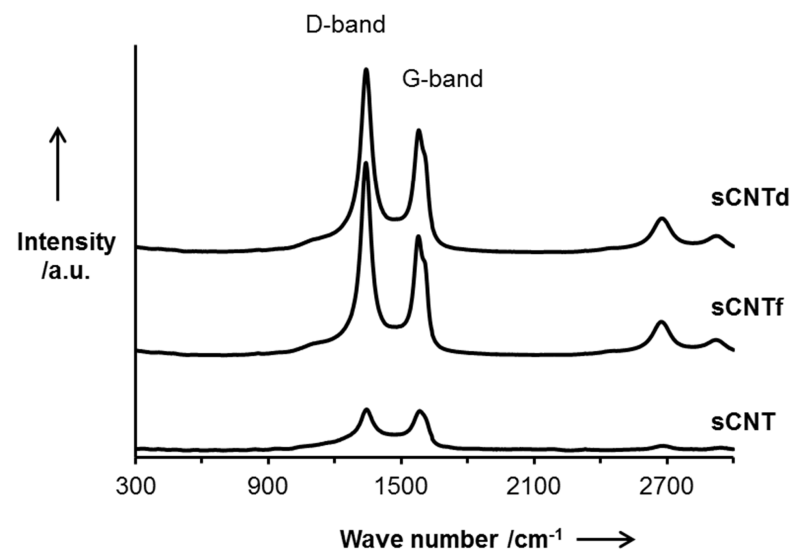

Figure S1. Raman spectra of small carbon nanotubes pristine (sCNT), functionalized (sCNTf), and desorbed (sCNTd) (a. u.: arbitrary units). 


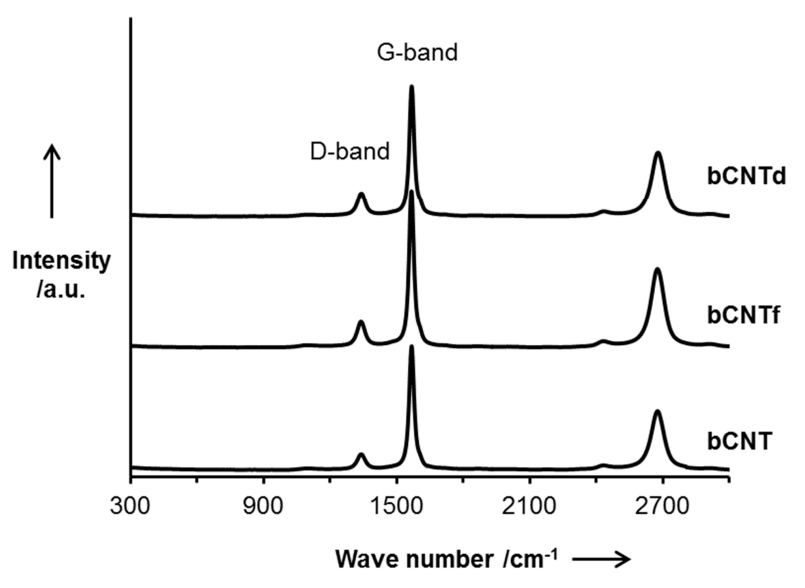

Figure S2. Raman spectra of the big carbon nanotubes pristine (bCNT), functionalized (bCNTf) and desorbed (bCNTd).

\section{THERMAL DESORPTION}

$\mathrm{CO}$ and $\mathrm{CO}_{2}$ peaks were shifted for the bCNTf and reduced in intensity compared to those of small CNT. Higher intensities of $\mathrm{CO}$ and $\mathrm{CO}_{2}$ releases were nonetheless observed when comparing bCNTf to bCNT and bCNTd (Figure S3). The shift in temperature observed for the gas desorption of small and big CNT was probably due the difference in carbon structure ${ }^{l}$. 


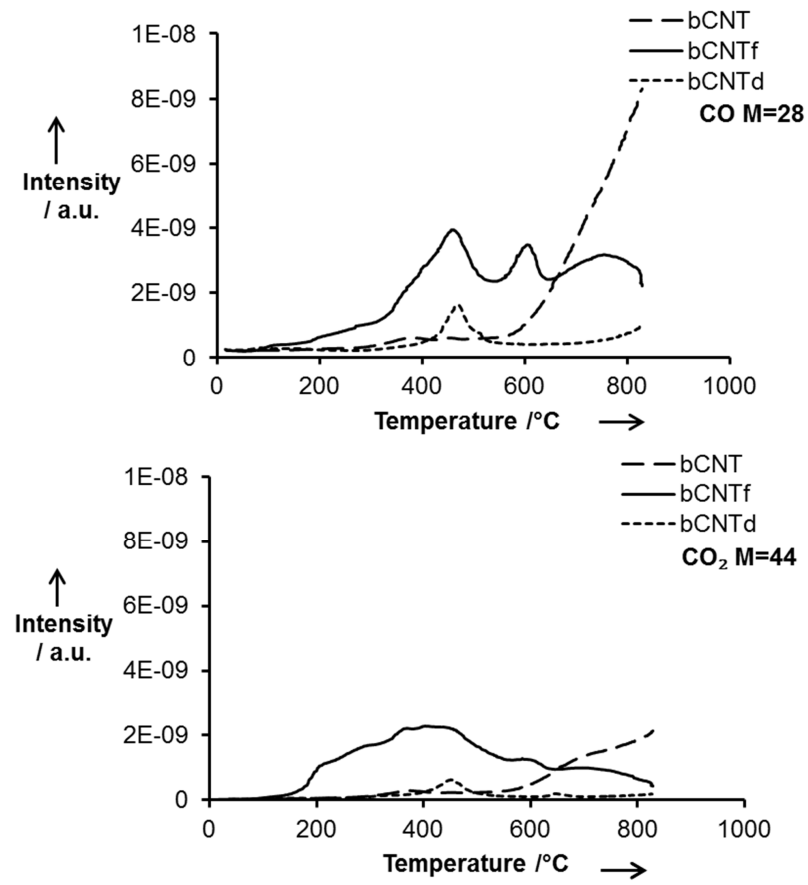

Figure S3. Thermal desorption of the big $\mathrm{CNT}, \mathrm{CO}$ and $\mathrm{CO}_{2}$ releases.

\section{MICROSCOPIC OBSERVATIONS OF RAW 264.7 CELLS}

A $24 \mathrm{~h}$ exposition of the cells to the smallest doses of CNT $(15 \mu \mathrm{g} / \mathrm{ml}$ for small CNT, and $30 \mu \mathrm{g} / \mathrm{L}$ for big CNT) was conducted directly on an 8-well chambered coverglass (Lab-Tek®). The cells were then rinsed twice with PBS, dried before a May-Grünwald Giemsa staining (MGG).

Optic microscopic images are presented in Figure S4. CNT interactions with the RAW macrophages were apparent: individual CNT and CNT agglomerates were preferentially located at the plasma surface of the cells. Small CNT whatever the surface treatment inducted a cellular uptake which could be associated probably with a phagocytosis process. Activated macrophages with visible vacuoles containing CNT agglomerates were identified. Long and thin pseudopods are believed to be due to the macrophages adherence rather than directly to phagocytosis. Few dead cells were also observed, but their number seemed lesser than for the big CNT. 
For the big CNT although some cells were activated, it was not obvious that phagocytosis occurred. Individual CNT were visible but neither those nor agglomerates were clearly observed into vacuoles. They could only adhere to the cell surface but hardly be engulfed by the macrophages. This is in accordance with the so-called frustrated phagocytosis known to happen with oversized CNT. Concerning the surface treatment, no clear difference in cell morphology was detected whatever the size of the CNT.

The same experiments were conducted for the highest doses of CNT $(120 \mu \mathrm{g} / \mathrm{mL}$ for small CNT and $240 \mu \mathrm{g} / \mathrm{mL}$ for big CNT). However, despite three washing, the coverglass remained too loaded by CNT to allow relevant observations.

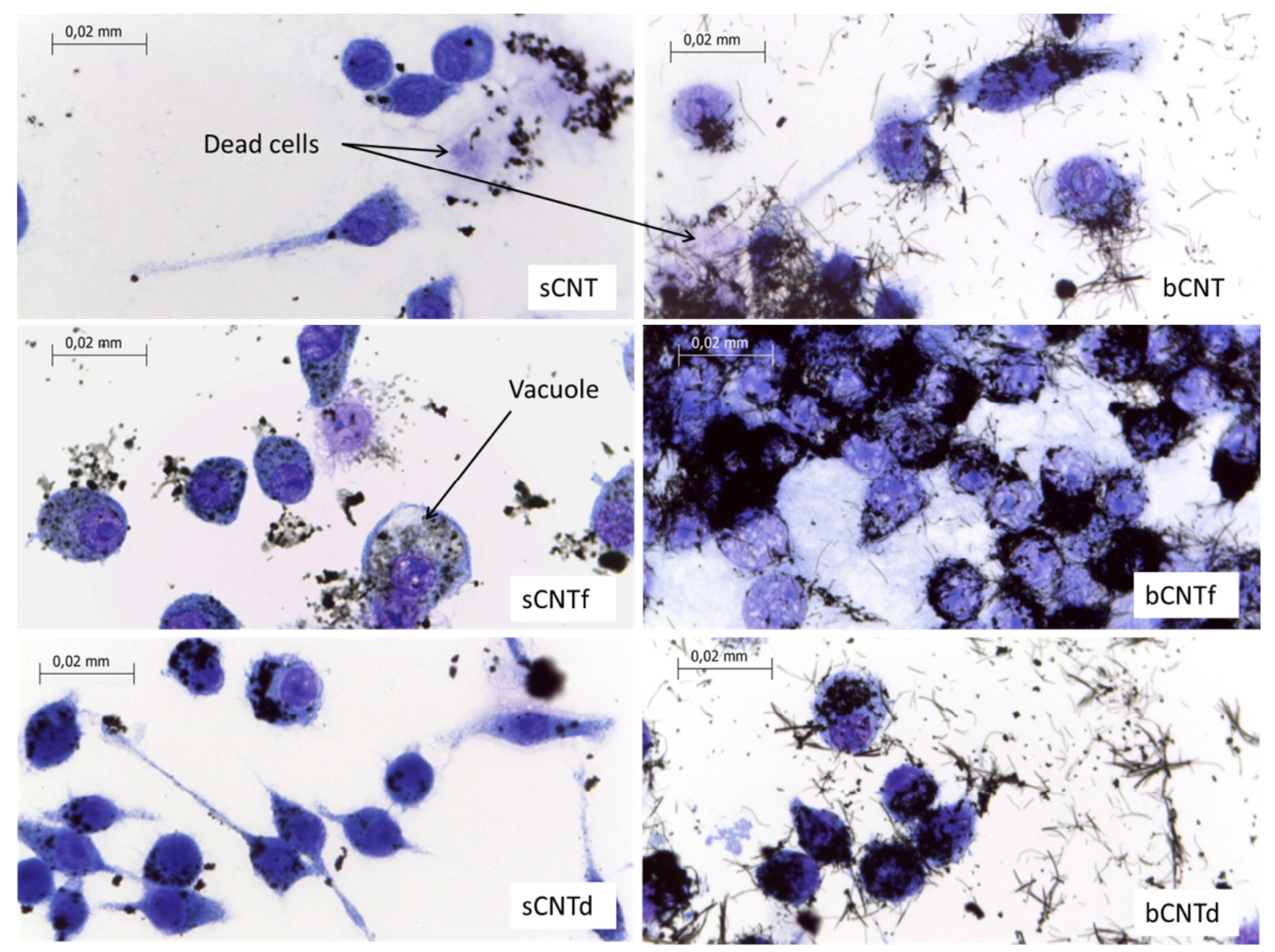

Figure S4. Microscopic images of RAW 264.7 cells exposed for $24 \mathrm{~h}$ to $15 \mu \mathrm{g} / \mathrm{mL}$ and $30 \mu \mathrm{g} / \mathrm{mL}$ of small and big CNT respectively after May-Grünwald-Giemsa staining. 


\section{BIAS CORRECTION FOR OXIDATIVE STRESS DETECTION}

Oxidative stress caused by carbon nanotubes was assessed by the detection of reactive oxygen species (ROS). An acellular test was developed in order to obtain correction from the strong bias due to the presence of $\mathrm{CNT}$ in the culture supernatant. An experiment was carried out to measure the variations between the fluorescence obtained for $0,10,100,1000 \mathrm{nM}$ standard curve of the fluorescent probe DCF (2',7'-dichlorodihydrofluorescein) realized in complemented medium without CNT and the biased fluorescence obtained after addition of carbon nanotubes in those DCF dilution. Corrections were calculated for each carbon nanotube type and each dose. An example for the pristine small carbon nanotubes is given in Figure S5, and the whole corrections are given in Table S1.

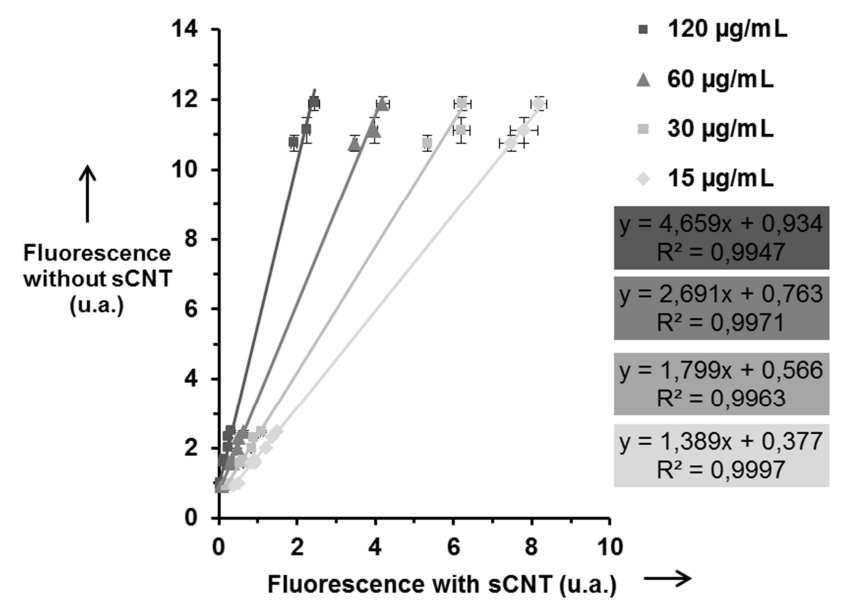

Figure S5. Bias between fluorescence of 0 to $10000 \mathrm{nM} \mathrm{DCF}$, with and without pristine small carbon nanotubes (sCNT).

Table S1. Corrections of bias in the oxidative stress detection assay $\left(\mathrm{R}^{2}>0.96\right.$; small carbon nanotubes pristine: sCNT, functionalized: sCNTf, desorbed: $\mathrm{sCNTd}$, big carbon nanotubes pristine: bCNT, functionalized: bCNTf, desorbed: bCNTd).

\begin{tabular}{|l|l|l|l|l|l|}
\hline Powder & $\begin{array}{l}\text { Correction at } \\
15 \mu \mathrm{g} / \mathrm{mL}\end{array}$ & $\begin{array}{l}\text { Correction at } \\
30 \mu \mathrm{g} / \mathrm{mL}\end{array}$ & $\begin{array}{l}\text { Correction at } \\
60 \mu \mathrm{g} / \mathrm{mL}\end{array}$ & $\begin{array}{l}\text { Correction at } \\
120 \mu \mathrm{g} / \mathrm{mL}\end{array}$ & $\begin{array}{l}\text { Correction at } \\
240 \mu \mathrm{g} / \mathrm{mL}\end{array}$ \\
\hline
\end{tabular}




\begin{tabular}{|c|c|c|c|c|c|}
\hline sCNT & $\begin{array}{l}y=1.389 x+ \\
0.377\end{array}$ & $\begin{array}{l}y=1.799 x+ \\
0.566\end{array}$ & $\begin{array}{l}y=2.691 x+ \\
0.763\end{array}$ & $\begin{array}{l}y=4.659 x+ \\
0.934\end{array}$ & I \\
\hline sCNTf & $\begin{array}{l}y=1.199 x+ \\
0.225\end{array}$ & $\begin{array}{l}y=1.400 x+ \\
0.357\end{array}$ & $\begin{array}{l}y=1.823 x+ \\
0.522\end{array}$ & $\begin{array}{l}y=2.660 x+ \\
0.638\end{array}$ & I \\
\hline sCNTd & $\begin{array}{l}y=1.031 x+ \\
0.266\end{array}$ & $\begin{array}{l}\mathrm{y}=1.072 \mathrm{x}+ \\
0.421\end{array}$ & $\begin{array}{l}y=1.165 x+ \\
0.623\end{array}$ & $\begin{array}{l}y=1.365 x+ \\
0.833\end{array}$ & I \\
\hline bCNT & I & $\begin{array}{l}y=1.267 x+ \\
0.291\end{array}$ & $\begin{array}{l}y=1.578 x+ \\
0.350\end{array}$ & $\begin{array}{l}y=2.214 x+ \\
0.437\end{array}$ & $\begin{array}{l}y=3.251 x+ \\
0.615\end{array}$ \\
\hline bCNTf & I & $\begin{array}{l}y=1.344 x+ \\
0.221\end{array}$ & $\begin{array}{l}y=1.752 x+ \\
0.277\end{array}$ & $\begin{array}{l}y=2.423 x+ \\
0.427\end{array}$ & $\begin{array}{l}y=3.678 x+ \\
0.655\end{array}$ \\
\hline bCNTd & I & $\begin{array}{l}y=1.341 x+ \\
0.215\end{array}$ & $\begin{array}{l}y=1.662 x+ \\
0.336\end{array}$ & $\begin{array}{l}y=2.340 x+ \\
0.492\end{array}$ & $\begin{array}{l}y=3.641 x+ \\
0.693\end{array}$ \\
\hline
\end{tabular}

\section{TOXICITY OUTCOMES WITH DOSES EXPRESSED IN SURFACE}

In Figure S6 and Figure S7 the LDH releases and TNF- $\alpha$ production induced by the six CNT are reported as a function of their surface, calculated thanks to the CNT specific surface area. The choice of dose metric for toxicity assays of nanoparticles is greatly discussed ${ }^{2,3}$. Surface is predominant at the nanoscale, but the only method to measure it by B.E.T. is imprecise, and mass dose currently remains the standard metric. 


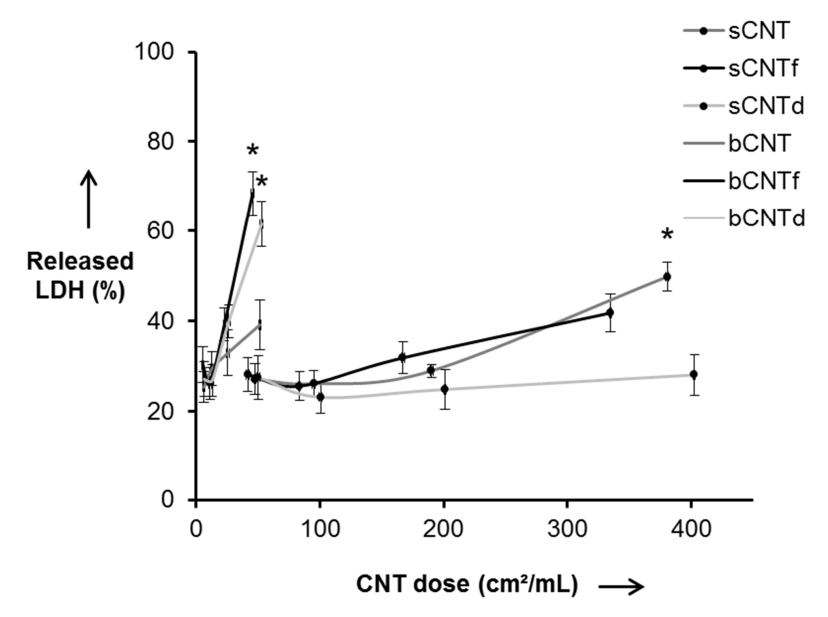

Figure S6. Cytotoxicity determined by LDH release after a $24 \mathrm{~h}$ exposition to CNT, reported to that of total cellular LDH measured after lyse of the negative control cells. Standard errors of the mean and statistical significant difference from the negative control $(n=3, * p<0.05)$ are specified on the graph.

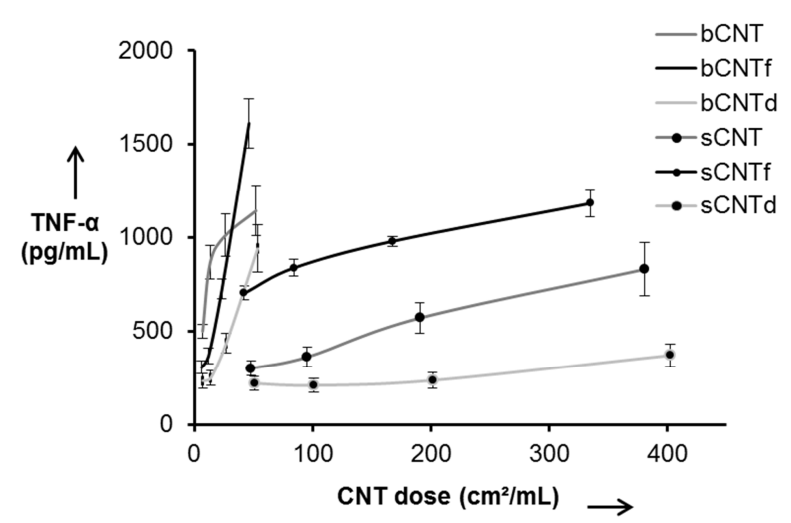

Figure S7. Inflammation determined by TNF- $\alpha$ production after a $24 \mathrm{~h}$ exposition to CNT. Standard errors of the mean $(n=3)$ are specified on the graph. Statistical significant differences were not indicated for more readability.

\section{REFERENCES}

(1) Boehm, H. P. (2002) Surface oxides on carbon and their analysis: a critical assessment, Carbon 40, $145-149$. 
(2) OECD. (2012) Guidance on sample preparation and dosimetry for the safety testing of manufactured nanomaterials, Series on the Safety of Manufactured Nanomaterials, Organisation for Economic Co-operation and Development, Paris.

(3) Flahaut, E. (2012) Factoring-in agglomeration of carbon nanotubes and nanofibers for better prediction of their toxicity versus asbestos. 